\title{
GCFR Coupled Neutronic and Thermal-Fluid-Dynamics Analyses for a Core Containing Minor Actinides
}

\author{
Diego Castelliti, ${ }^{1,2}$ Eleonora Bomboni, ${ }^{1}$ Nicola Cerullo,, ${ }^{1,3}$ Guglielmo Lomonaco, ${ }^{1}$ \\ and Carlo Parisi ${ }^{4}$ \\ ${ }^{1}$ Dipartimento di Ingegneria Meccanica, Nucleare e della Produzione (DIMNP), Università di Pisa (UNIPI), \\ CIRTEN, Largo Lucio Lazzarino n. 1, 56126 Pisa, Italy \\ ${ }^{2}$ Studiecentrum voor Kernenergie, Centre d'Etude de l'énergie Nucléaire (SCK CEN), Belgium \\ ${ }^{3}$ Dipartimento di Ingegneria della Produzione, Termoenergetica e Modelli Matematici (DIPTEM), Università di Genova (UNIGE), \\ Via all'Opera Pia n. 15/a, 16145 Genova, Italy \\ ${ }^{4}$ Gruppo di Ricerca Nucleare San Piero a Grado (GRNSPG), Università di Pisa (UNIPI), \\ Largo Lucio Lazzarino n. 1, 56126 Pisa, Italy
}

Correspondence should be addressed to Nicola Cerullo, cerullo@docenti.ing.unipi.it

Received 27 January 2009; Accepted 2 March 2009

Recommended by Jan Leen Kloosterman

Problems about future energy availability, climate changes, and air quality seem to play an important role in energy production. While current reactor generations provide a guaranteed and economical energy production, new nuclear power plant generation would increase the ways and purposes in which nuclear energy can be used. To explore these new technological applications, several governments, industries, and research communities decided to contribute to the next reactor generation, called "Generation IV." Among the six Gen-IV reactor designs, the Gas Cooled Fast Reactor (GCFR) uses a direct-cycle helium turbine for electricity generation and for a $\mathrm{CO}_{2}$-free thermochemical production of hydrogen. Additionally, the use of a fast spectrum allows actinides transmutation, minimizing the production of long-lived radioactive waste in an integrated fuel cycle. This paper presents an analysis of GCFR fuel cycle optimization and of a thermal-hydraulic of a GCFR-prototype under steady-state and transient conditions. The fuel cycle optimization was performed to assess the capability of the GCFR to transmute MAs, while the thermal-hydraulic analysis was performed to investigate the reactor and the safety systems behavior during a LOFA. Preliminary results show that limited quantities of MA are not affecting significantly the thermal-fluid-dynamics behavior of a GCFR core.

Copyright ( 2009 Diego Castelliti et al. This is an open access article distributed under the Creative Commons Attribution License, which permits unrestricted use, distribution, and reproduction in any medium, provided the original work is properly cited.

\section{Introduction: The Generation IV Project}

Generation IV proposals have been specifically advanced in order to meet the new challenges for nuclear energy production, increasing also the ways and purposes in which nuclear energy can be used. Six new reactor designs have been proposed, all of them aiming to satisfy requirements of reliability, sustainability, economics, and resistance to proliferation that characterize the Gen IV [1].

Among the six Gen IV reactor projects, there are two with a thermal neutronic spectrum (High, Temperature Gas Reactor (HTGR), Supercritical Water Reactor (SCWR)), three with a fast spectrum (Gas-Cooled Fast Reactor (GCFR),
Sodium Fast Reactor (SFR), Lead Fast Reactor (LFR)), and one with epithermal spectrum (Molten Salt Reactor (MSR)).

An important Gen IV target is Minor Actinides (MAs) transmutation. This paper presents an analysis of the GCFR fuel cycle with MAs and a thermal-hydraulic analysis of a GCFR-prototype, charged with such composed fuel, under steady-state and transient conditions. The fuel cycle has been designed in order to asses the capability of the GCFR to transmute MAs, while the thermal-hydraulic investigation was performed in order to investigate the reactor and the safety system behaviors during one of the Design Basis Accidents (DBAs), the Loss-of-Flow Accident (LOFA). Sensitivity analyses are also presented for assessing the effects 


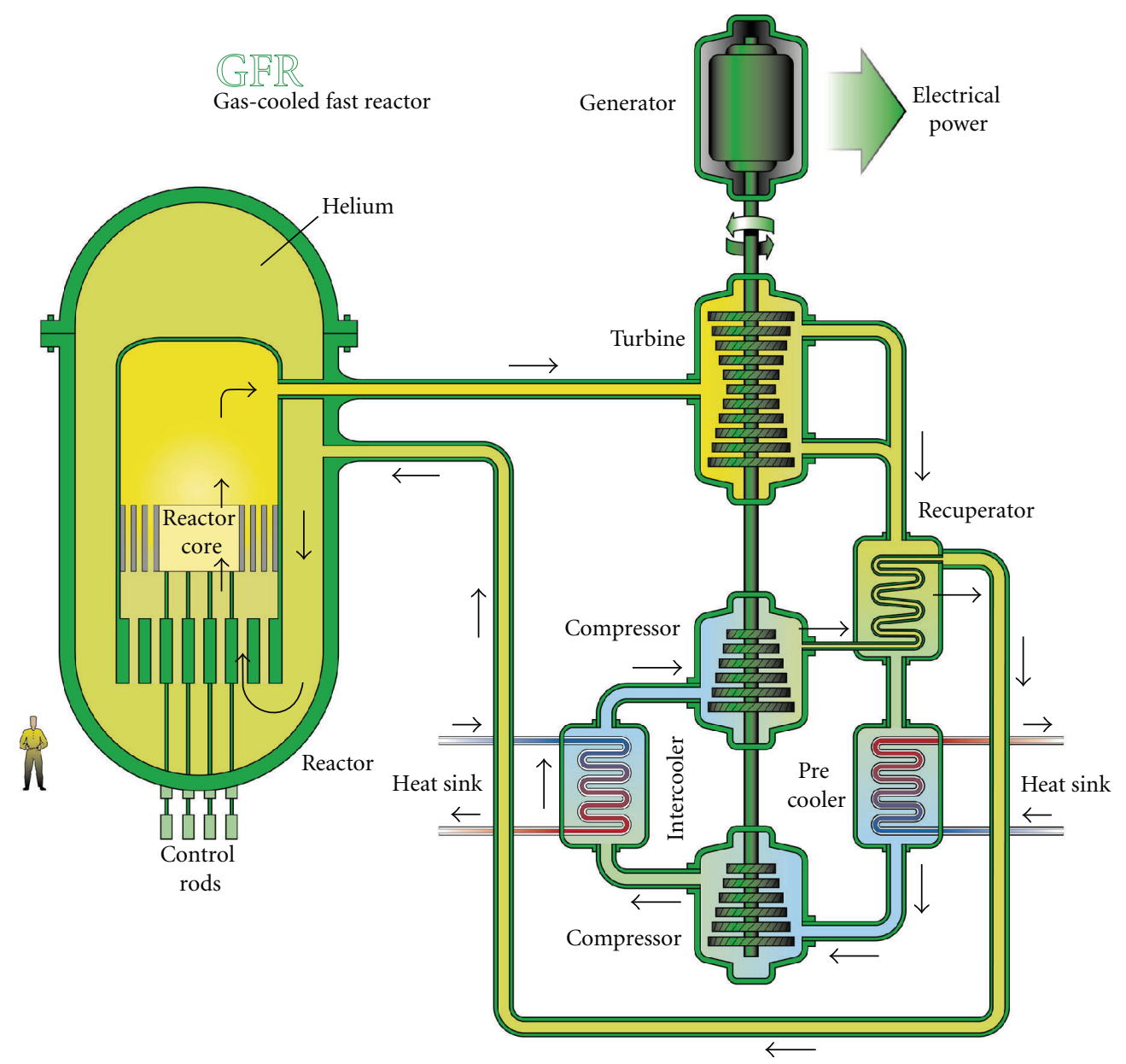

Figure 1: GCFR scheme [3].

of the presence of different MAs concentration on the fuel performance.

\section{The Gas-Cooled Fast Reactor}

Generation IV reactor projects are finalized to answer to new challenges that nuclear energy must face in this new century. Those mandatory projects have to meet Gen IV criteria [1], namely:
(1) sustainability;
(2) economics;
(3) proliferation-resistance;
(4) reliability.

Criteria (1), (2), and (3) include, as important target, the MAs transmutation.

The capability of removing the heat produced in the core (both in nominal and accidental conditions) is a key point (particularly for this reactor) of criterion (4); this work (in conjunction with what already published in [2]) gives a positive (even if still partial) answer to this request.

The GCFR proposed in the frame of Gen IV initiative (Figure 1) uses a direct-cycle helium turbine for electricity generation. This reactor can be employed both for electricity generation and in $\mathrm{CO}_{2}$-free thermochemical production of hydrogen. Besides, the use of a fast spectrum allows the transmutation of the actinides, minimizing the long-lived radioactive waste production in an integrated fuel cycle (one of main targets of Gen IV).

Furthermore, the GCFR fast spectrum makes the use of available fissile and fertile materials (including depleted uranium) possible in a more efficient way compared to the thermal reactors. GCFR has better safety features than liquid metals reactor, and it can be quite flexible in $\mathrm{Pu}$ management [3].

The GCFR has a high power density, about $100 \mathrm{KW} / \mathrm{l}$, similar to a PWR, but in this case the power has to be removed by a noncondensable gas (helium) instead of water.

The proposed GCFR initial design shares several components with HTGR technology, and it uses a direct Brayton cycle (without any Intermediate Heat Exchanger, or IHX). This allows to combine a high thermal efficiency (thanks to the high coolant temperatures) with a high MAs transmutation and fertilization rate (thanks to the fast neutron spectrum). The high coolant output temperatures make the reactor suitable for industrial applications, too. 


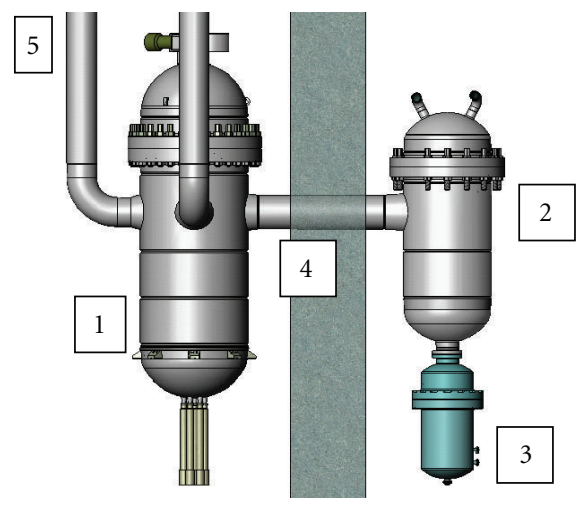

FIGURE 2: : ETDR plant overview [12].

However, the direct Brayton cycle design is considered very challenging; so a "more conventional" version with a $\mathrm{He}, \mathrm{N}_{2}$, or $\mathrm{CO}_{2}$ secondary loop could be preferred [4]. The inevitable performance loss is accepted, in order to achieve better plant safety features. The ETDR experimental facility moves in this direction (see Section 3).

Preliminary analysis results confirmed that it is possible to have a self-breeding core without any fertile blanket (i.e., Breeding Gain slightly greater than zero in order to meet nonproliferation constraints) from a starting fuel based on $\mathrm{Pu}$ and depleted U. More details on proposed technical solutions for GCFR can be found in [3, 5-11].

\section{ETDR: Core and Plant Characteristics}

Actual realization of a commercial GCFR is scheduled not before the year 2040. An experimental and demonstration facility is scheduled for the year 2020, with the purpose to test the technical solutions proposed for the GCFR concept. The name of this demonstration facility is Experimental and Testing Demonstration Reactor (ETDR). The ETDR will represent a milestone on the way approaching the final GCFR configuration, thanks to the numerous technical solutions that will be tested despite a quite different power size. While the GCFR is projected to have a nominal thermal power of 2400 (or 3000) $\mathrm{MW}_{\text {th }}\left(600 \mathrm{MW}_{\text {th }}\right.$ in the modular version), ETDR nominal power will be limited at $50 \mathrm{MW}_{\text {th }}$, with no electricity production and a secondary water-cooled loop. It will be the first gas cooled, fast neutron spectrumnuclear plant ever built.

ETDR plant scheme is illustrated in Figure 2.

In Figures 1, 2 and 3 we can recognize.

(1) core and vessel;

(2) main heat exchanger;

(3) main blower;

(4) main cross duct;

(5) decay heat removal loop;

(6) decay heat removal blower (supposed inactive in the LOFA transient);

(7) tertiary air cooling system (not modeled). [10].

A more detailed ETDR plant description can be found in

Decay Heat Removal (DHR) system is composed by three loops $(3 \times 100 \%$ redundancy) connected to vessel and should have the same design that will be installed on the commercial $600 \mathrm{MW}_{\text {th }}$ GCFR. One of those three loops has no blowers and it relies on natural circulation (NC) only (full passive system), while the second loop is equipped with a blower that is supposed to work only for 24 hours after the DHR valve is opened (few seconds later incidental event) and before NC takes place. Finally, the third DHR loop is totally based on active safety systems (blower). The NC loop is particularly efficient in transient events where there is not a fast depressurization of primary circuit (structural integrity preserved), while active devices are especially suitable for fast depressurization events (LOCA) (Blower in second loop is meant to work with a system residual pressure of about $7 \div 10$ bars (SBLOCA), while blower in third loop can work with He at nearly 1 bar (LBLOCA), requiring a higher pumping power.)

As previously said, DHR system is connected to the reactor pressure vessel (RPV). Hot leg is connected to the upper plenum, while helium from cold leg flows into downcomer. Therefore the core is cooled by bottom-to-top coolant flow. During normal operation, reactor power is removed via a counter-current U-tubes helium-water HX. The secondary side is then cooled by forced air circulation.

Concerning the DHR HXs, the primary to secondary heat removal is achieved by the use of counter-current straight vertical tubes helium-water HX. NC is established thanks to difference of $15 \mathrm{~m}$ between the primary and secondary side thermal barycenters.

DHR secondary circuit, containing water pressurized at 10 bars, is exchanging the removed power from the primary side with the final heat sink, a water pool at atmospheric pressure. The height difference between secondary-side thermal barycenters is about $4 \mathrm{~m}$.

\section{ETDR: Core Fuelled with Minor Actinides}

Several studies and calculations have been performed on thermal-hydraulics of ETDR systems, both in steady-state and transients conditions, but most of these analyses have not considered any neutronic feedback in the core.

We tried to obtain some results by analyzing a core charged with a small quantity of MA. (In the present design it is not possible to exceed $10 \%$ of MAs content because of reactor control problems.) In fact, one of most important features of this system is the capability to burn MAs, greatly reducing wastes and producing energy by fast fissions as well.

In order to make some preliminary evaluations of the dynamic effects on a GCFR core due to MAs presence in the fuel, we performed some point neutron kinetics(NK-)TH calculations on the ETDR design. For comparison purposes, we chose to analyze Steady State and a LOFA transient because there are validated data already available for these cases [2]. Neutronic data (Doppler coefficient, void coefficient, etc.) implemented in our calculations are taken 


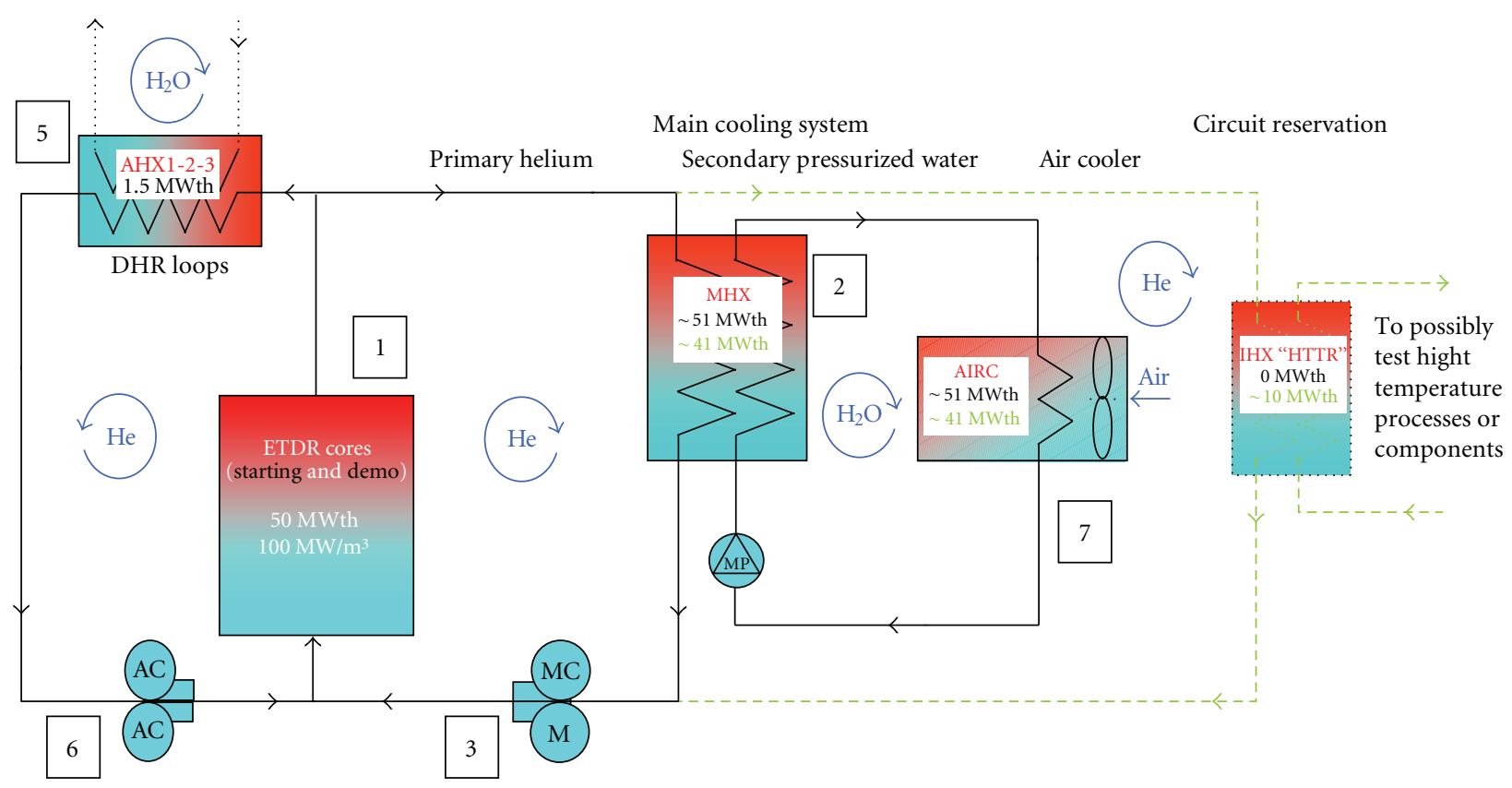

Figure 3: ETDR flux diagram [12].

from the MCNP calculations performed for the GCFR core $\left(600 \mathrm{MH}_{\text {th }}\right)$ see $[3,5-11]$. As already anticipated, to perform a complete ETDR LOFA analysis [2], a point NK analysis is necessary, taking into account the variations of reactivity coefficients (e.g., Doppler and void coefficients) due to the fuel isotopic changes.

Calculations were performed with and without the presence of MAs in the fuel. The code used for the point NKTH calculations was the RELAP5-3D [13] .

We performed, at first, MCNP5 [14] calculations, assessing Doppler and void coefficients, delayed neutron fractions, and prompt neutron average life, in order to run a point NK-TH calculation. We considered, at first, isotope mass fractions shown in Table 1 (first column, LWR discharge). This composition appears to be quite performing, according to criticality, as previously shown in [15].

In conclusion, we assumed, from MCNP calculations.

(i) Delayed neutron fraction $\beta=332 \mathrm{pcm}$.

(ii) Prompt neutron average life $=0.364 \mu \mathrm{s}$.

(iii) Reactivity insertion from $1200 \mathrm{~K}$ to $500 \mathrm{~K}=+98 \mathrm{pcm}$.

(iv) Reactivity insertion from full depressurization $(7.0 \mathrm{MPa} \rightarrow 0.1 \mathrm{MPa})=+68 \mathrm{pcm}$.

Then, these data were used as input for the point NK model.

\section{RELAP-3D Model Used}

For the thermal-hydraulic calculations, a RELAP-3D model has been built, based on the start-up core design [16]. The model is illustrated in Figure 4.
The RELAP5-3D nodalization of the ETDR reactor can be divided in the following blocks:

(i) vessel and core (components from 100 to 240);

(ii) main cross duct (component 250, 450, 480);

(iii) main heat exchanger (primary side and secondary side components from 290 to 400 and from 700 to 760);

(iv) blower (component 350);

(v) decay heat removal system (components from 800 to 880 and from 900 to 999 ).

It is important to note that secondary system has been modeled as boundary condition.

\section{Point-NK TH Steady State Calculations with and without MA}

Three calculations have been performed:

(1) "imposed power" calculation (performed with no NK data. The $50 \mathrm{MW}$ reactor power is provided with no neutronic feedbacks; so power is constant, and system does not "feel" any changes in reactivity due to neutronic feedback);

(2) reference core composition with NK feedbacks added;

(3) reference core with MA and NK feedbacks added (different fuel composition; see Section 4).

A comparison between those calculations is shown in Table 2 . 


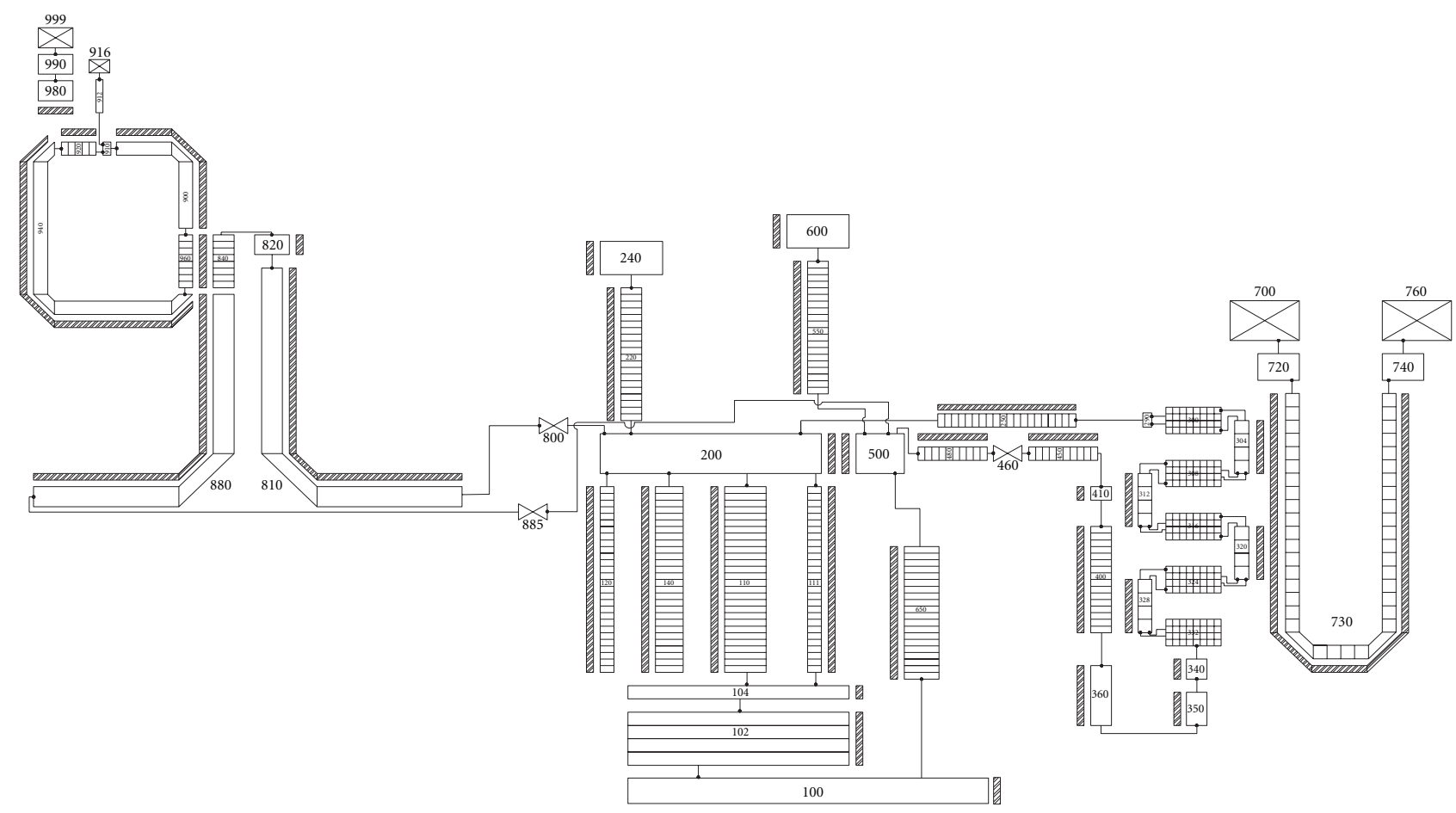

Figure 4: RELAP5-3D ETDR nodalization [10].

TABle 1: Core isotopic compositions considered [15]

\begin{tabular}{lcc}
\hline Isotope & $\begin{array}{c}\text { Mass fraction LWR } \\
\text { discharge }(\%)\end{array}$ & $\begin{array}{c}\text { Mass fraction } 5 \% \\
\text { MAs }(\%)\end{array}$ \\
\hline $\mathrm{U}^{235}$ & 0.2 & 0.571 \\
$\mathrm{U}^{238}$ & 79.811 & 80.991 \\
$\mathrm{~Np}^{237}$ & 0.92 & 0.87 \\
$\mathrm{Pu}^{238}$ & 0.46 & 0.446 \\
$\mathrm{Pu}^{239}$ & 9.804 & 9.251 \\
$\mathrm{Pu}^{240}$ & 4.302 & 4.278 \\
$\mathrm{Pu}^{241}$ & 2.281 & 1.222 \\
$\mathrm{Pu}^{242}$ & 1.241 & 1.206 \\
$\mathrm{AM}^{241}$ & 0.56 & - \\
$\mathrm{AM}^{242 \mathrm{~m}}$ & - & 0.017 \\
$\mathrm{AM}^{243}$ & 0.32 & 0.81 \\
$\mathrm{Cm}^{242}$ & - & 0.001 \\
$\mathrm{Cm}^{243}$ & - & 0.002 \\
$\mathrm{Cm}^{244}$ & 0.1 & 0.265 \\
$\mathrm{Cm}^{245}$ & - & 0.065 \\
$\mathrm{Cm}^{246}$ & - & 0.005 \\
\hline
\end{tabular}

As it can be seen above, the differences between all the relevant $\mathrm{TH}$ parameters are negligible, even with different fuel vectors $(\rightarrow$ different neutronic feedbacks, different reactivity insertions).

It is interesting to notice that adding the MA into the fuel is not affecting the safety relevant parameters (e.g., cladding and fuel temperatures). Therefore reactor safetyrelated steady state $\mathrm{TH}$ parameters are roughly independent in the range of considered fuel compositions.

\section{Point-NK TH LOFA Calculations}

In the previous paragraph we showed that the introduction of small quantities of MAs in the fuel will have substantially no effect on the steady state calculations. No particular differences were also found comparing two scram curves, one with standard imposed decay heat [10] and the other one considering the effects of the small fractions of MAs. The difference of relative power (relative error) is never going beyond $1.4 \%[10]$.

We present now, in the following figures, LOFA transient analyses performed with the MAs concentration illustrated in Table 1, compared with results from the standard imposed scram curve.

LOFA analyses were performed using the run-down blower curve provided by CEA [2].

The sequence of events leading to the LOFA transient is hereafter illustrated (the steady state condition is achieved after about 50 seconds. Transient sequence is started at second 378 of run (as suggested by benchmark data [16])):

(1) time 0 second: main blower loss of power;

(2) time 0.75 second: reactor scram (relative blower speed going below $90 \%$ );

(3) time 173.66 second: closure of main loop valves and opening of DHR loop valves. 
Table 2: Point Neutron Kinetics (NK) core parameters (with and without MA)

\begin{tabular}{lccc}
\hline Parameters & Imposed power & Reference core (point NK values) & Reference core + MA (point NK values) \\
\hline Reactor power & $50 \mathrm{MW}$ & $50.02 \mathrm{MW}$ & $50.02 \mathrm{MW}$ \\
Total system flow rate & $32.10 \mathrm{Kg} / \mathrm{s}$ & $32.13 \mathrm{Kg} / \mathrm{s}$ & $32.11 \mathrm{Kg} / \mathrm{s}$ \\
Flow rate in hot channel & $0.581 \mathrm{Kg} / \mathrm{s}$ & $0.581 \mathrm{Kg} / \mathrm{s}$ & $0.581 \mathrm{Kg} / \mathrm{s}$ \\
Flow rate in average channel & $0.595 \mathrm{Kg} / \mathrm{s}$ & $0.595 \mathrm{Kg} / \mathrm{s}$ & $0.595 \mathrm{Kg} / \mathrm{s}$ \\
Reactor pressure at top of vessel & $6.92 \mathrm{MPa}$ & $6.924 \mathrm{MPa}$ & $6.92 \mathrm{MPa}$ \\
Reactor mass of coolant without DHR & $389.75 \mathrm{Kg}$ & $389.75 \mathrm{Kg}$ & $389.75 \mathrm{Kg}$ \\
Reactor mass of coolant with DHR & $473.54 \mathrm{Kg}$ & $473.54 \mathrm{Kg}$ & $473.54 \mathrm{Kg}$ \\
Core inlet temperature & 263.9 & 263.1 & 262.8 \\
Core average exit temperature & 563.7 & 564.5 & 564.6 \\
Coolant temp rise in the core & 299.8 & 300.5 & 299.3 \\
Exit coolant temp in hot channel & 615.6 & 616.5 & 616.6 \\
Exit coolant temp in avg. Channel & 562.7 & 563.5 & 563.6 \\
Max clad temp in hot channel & 687.6 & 693.5 & 691.7 \\
Max clad temp in avg. channel & 621.2 & 626.5 & 624.9 \\
Max fuel temp in hot channel & 1069.5 & 1073.9 & 1070.4 \\
Max fuel temp in avg. channel & 946.0 & 949.9 & 946.8 \\
Main blower speed & $523.6 \mathrm{rad} / \mathrm{s}$ & $523.6 \mathrm{rad} / \mathrm{s}$ & $523.6 \mathrm{rad} / \mathrm{s}$ \\
Main blower rated head & $8007.8 \mathrm{~m}{ }^{2} / \mathrm{s}^{2}$ & $2024.2 \mathrm{~Pa} \cdot \mathrm{m}^{3}$ & $8319 \mathrm{~m}^{2} / \mathrm{s}^{2}$ \\
Main blower rated torque & $2009.1 \mathrm{~Pa} \cdot \mathrm{m}^{3}$ & $157.3 \mathrm{~m}^{2}$ & $2024.5 \mathrm{~Pa} \cdot \mathrm{m}^{3}$ \\
MHX heat transfer area & $157.3 \mathrm{~m}{ }^{2}$ & & $157.3 \mathrm{~m}{ }^{2}$ \\
\hline
\end{tabular}

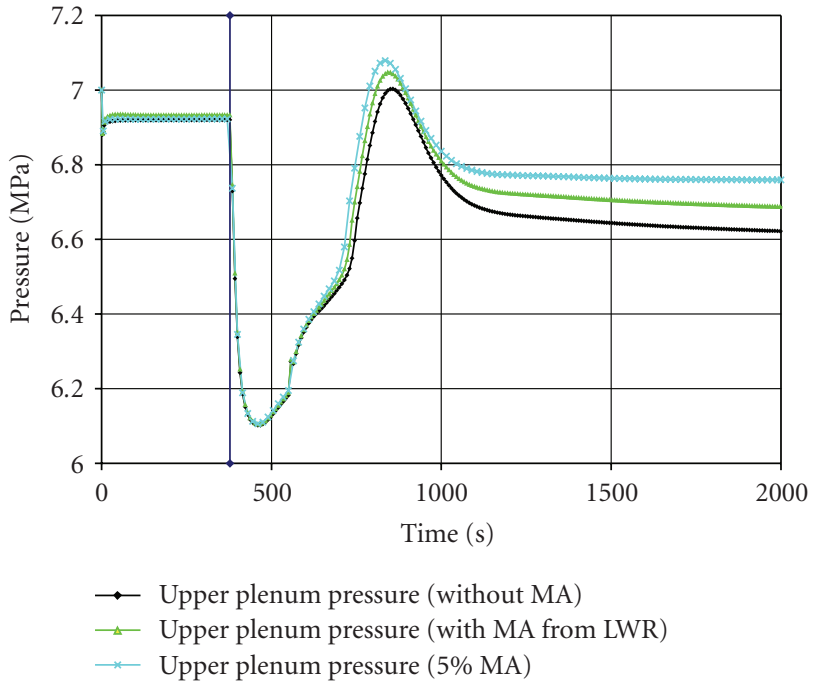

Figure 5: Pressure at the top of the vessel.

It should be noted that we perform the MAs analyses referring to a concentration deriving from a typical LWR discharge (see Table 1) and to an imposed concentration of $5 \%$ of MAs in the fuel composition.

Some differences are expected because of the different isotopic composition of compared fuels, leading to different decay head profiles: in detail, higher pressures and temperatures are expected from the presence of higher quantity of MAs in the fuel, especially in the third transient phase (long term cooling), because of the higher activity in the fuel.

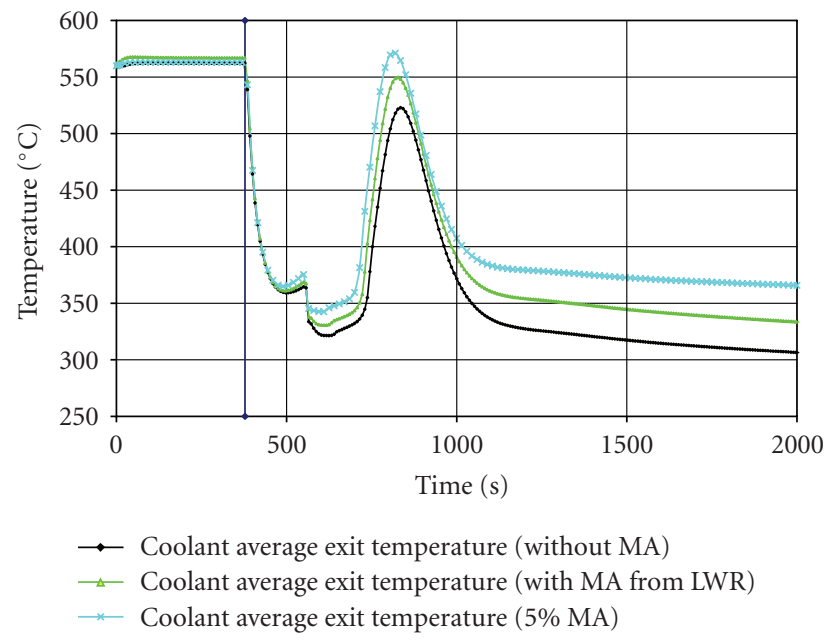

FIgURE 6: Core average exit temperature.

In the next figures, the LOFA transient evolution is shown. After the scram event, pressure and temperatures in the primary system start to drop, due to the stopped power generation in fuel. Before the closure of main circuit valves and opening of DHR valves, we can notice $(\sim 100$ seconds after scram) pressures and temperatures to start rising again, because of mass flow becoming too low.

After 173 seconds after scram, blower relative rotational velocity falls below $10 \%$, allowing the main valves to close and the DHR circuit to be opened, thus starting the insetting of Natural Circulation (NC). 


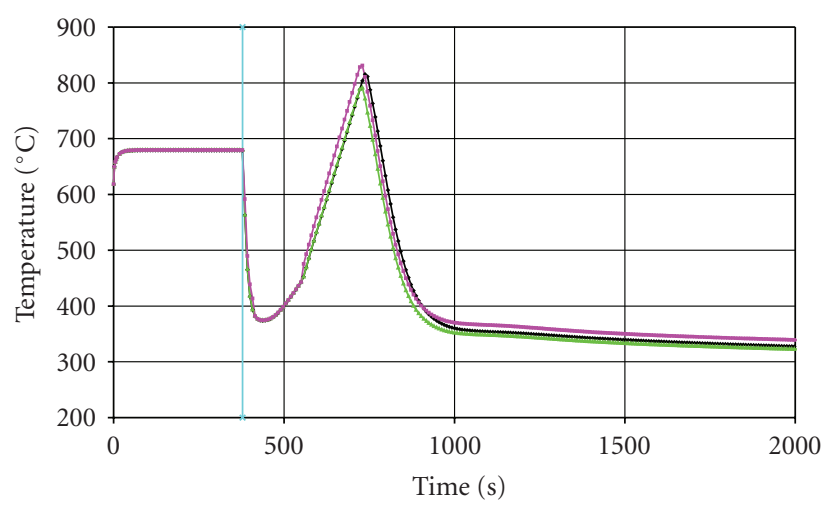

$\rightarrow$ Max cladding temperature in hot channel (without MA)

$\triangle$ Max cladding temperature in hot channel (with MA from LWR)

$\rightarrow-$ Max cladding temperature in hot channel (5\% MA)

FIgURE 7: Maximum fuel temperature in hot channel.

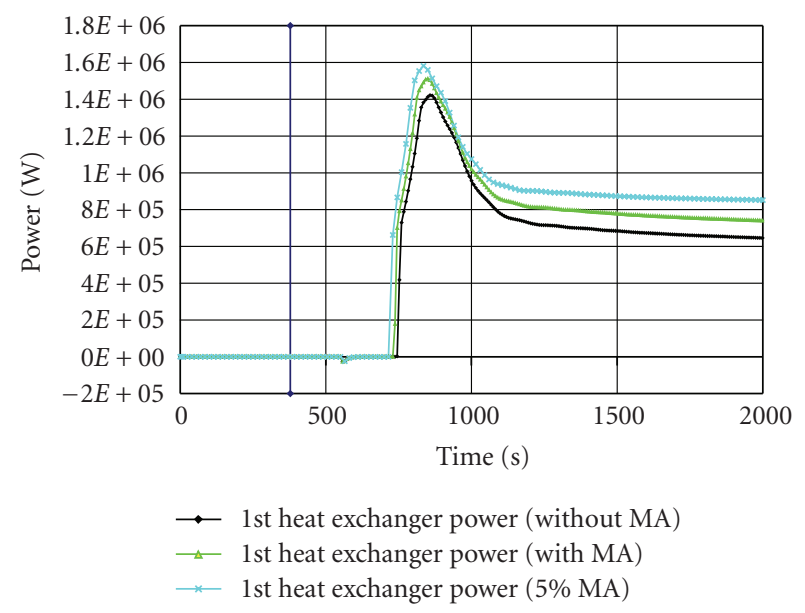

Figure 8: Exchanged power in 1st DHR HX.

Helium in DHR tubes starts flowing downwards because of lower temperature and higher pressure than core, refraining the NC to incur and causing the raise of pressure and temperature (see Figures 4, 5 and 6).

Eventually, after $\sim 470$ seconds from start of transient, conditions are met for the $\mathrm{NC}$ to incur, starting the long term cooling phase.

In Figure 5, the behavior of pressure at top of the RPV for different types of fuels is shown. The increasing pressure in the RPV is due to greater decay heat of MA isotopes.

Also the rising of core average exit temperature (Figure 6) is the consequence of the same cause.

The curve in Figure 7 shows that the most important parameter of the thermal-fluid-dynamics core design (maximum clading temperature in hot channel) is basically the same for all the analyzed situations.

Figures 8 and 9 show the power exchanged in both DHR HXs (primary-secondary side helium-water HX and secondary-final heat sink water-water HX), showing the convergence of the exchanged power.

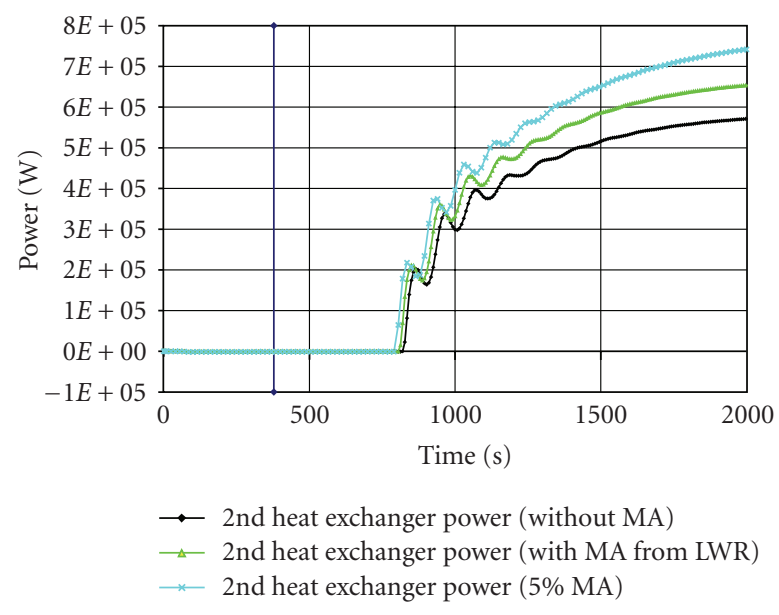

FIGURE 9: Exchanged power in 2nd DHR HX.

\section{Conclusions}

From the calculations we can note that there are no relevant differences in both steady state and transient behavior between cases with and without MAs inside the fresh fuel.

The transient analyses showed that a limited insertion of MAs ( $5 \%)$ does not significantly affect transient behavior of a GCFR system. Small differences are noticed after about 400 seconds from the LOFA starting point, when NC occurs. In addition very small pressure differences were identified $(0.04 \mathrm{MPa})$, and they are mostly due to a higher residual pressure in the system and to higher coolant, cladding, and fuel temperatures (about 20 higher than the reference case).

DHR system performed well under all analyzed cases. Generally speaking the capability of removing the relevant amount of heat produced in the core (both in nominal and LOFA conditions) is demonstrated even in presence of (relatively) limited amount of MAs.

In conclusion, we can state that the influence of adding limited quantities of MAs is negligible considering the proposed GCFR design.

The MA quantity that can be added is currently limited by safety and control problems related to lower $\beta$ values for MA. Therefore further investigations about this topic could clarify the capabilities of GCFR system in increasing the MA input quantities. In that case the (foreseen) introduction of greater quantities of MA into the fuel for maximizing transmutation should be supported by a larger set of neutronic and thermal-hydraulic analyses.

\section{Acknowledgments}

The work presented in this paper has been partially funded by the European Union Sixth Framework Program under contracts GCFR and PuMA. The authors would like to thank Professor P. Coddington of PSI, Dr. C. Mitchell of AMEC-NNC, Professor J. L. Kloosterman of TUD, and Dr. J. Kuijper of NRG for their support and collaboration. The authors also thank Professor G. Forasassi of DIMNP for useful discussions and Professor F. D'Auria of GRNSPG for his precious suggestions and help in using RELAP5-3D code. 


\section{References}

[1] Generation IV Official, http://www.gen-4.org/index.html.

[2] E. Bubelis, D. Castelliti, P. Coddington, et al., "A GFR benchmark comparison of transient analysis codes based on the ETDR concept," in Proceedings of the International Congress on Advances in Nuclear Power Plants (ICAPP '07), vol. 3, pp. 1916-1925, Nice, France, May 2007.

[3] C. Poette, B. Mathieu, J. C. Garnier, A. Conti, and J. P. Gaillard, "Preliminary design of an advanced gas cooled fast reactorcores, fuel forms and primary system concepts," in Proceedings of the International Congress on Advances in Nuclear Power Plants (ICAPP '03), Córdoba, Spain, May 2003.

[4] J. Y. Malo, N. Alpy, F. Bertrand, et al., "Gas cooled fast reactor $2400 \mathrm{MWth}$, end of the preliminary viability phase," in Proceedings of the International Congress on Advances in Nuclear Power Plants (ICAPP '08), Anaheim, Calif, USA, June 2008.

[5] J. C. Bosq, A. Conti, G. Rimpault, J. C. Garnier, and J. Rouault, "Status of GFR design work at CEA: core physics studies (600-2400 MWth)," in Seminario GFR/ETDR, CEACadarache, France, Novembre 2004.

[6] A. Conti and J. C. Bosq, "600 MWth GFR cores containing plates CERCER-characteristics," CEA-Cadarache, France, December 2004.

[7] J. C. Garnier and J. Rouault, "The Gen IV GFR program," in Seminario GFR/ETDR, CEA-Cadarache, France, Novembre 2004.

[8] P. Dumaz, P. Allègre, C. Bassi, J. C. Garnier, and J. Y. Malo, "DHR studies and design integration for the GFR," in Seminario GFR/ETDR, CEA-Cadarache, France, Novembre 2004.

[9] A. Conti and A. Ravenet, "GCFR fuel element and sub-assembly concepts," in Seminario GFR/ETDR, CEACadarache, France, Novembre 2004.

[10] D. Castelliti, Il reattore GCFR (a gas a spettro veloce). Gli aspetti termofluidodinamici ed il suo contributo al bruciamento delle scorie nucleari, M.S. thesis, Università di Pisa, Pisa, Italy, 2007, http://etd.adm.unipi.it/theses/available/etd-05112007113534.

[11] J. P. Gaillard, G. Mignot, and A. Conti, "Thermal-hydraulic design of a gas cooled fast reactor," in Proceedings of the International Congress on Advances in Nuclear Power Plants (ICAPP '03), Córdoba, Spain, May 2003.

[12] G. Lomonaco, Analisi termofluidodinamica dei reattori nucleari innovativi refrigerati a gas, $\mathrm{Ph}$. D. thesis, Università di Pisa, Pisa, Italy, 2007, http://www.tesionline.it/default/tesi .asp?idt $=17893$.

[13] Idaho National Engineering and Environmental Laboratory, RELAP5-3D Code Development Team, "RELAP5-3D C Code Manual. Volume I: Code Structure, System Models, and Solution Methods," INEEL-EXT-98-00834, Rev. 2.4, June 2005.

[14] J. F. Briefmeister, "MCNP-A General Monte Carlo N-Particle Transport Code, Version 5," Tech. Rep. LA-CP-03-0245, Los Alamos National Laboratory, Los Alamos, NM, USA, 2003.

[15] N. Cerullo, G. Lomonaco, and E. Bomboni, "CIRTEN Contribution to WP1.1 Task 4," GCFR EU Project, Pisa, Italy, November 2006, http://www.gcfr.org/.

[16] C. Poette, C. Bassi, J. Y. Malo, and F. Morin, "GCFR FP6 ETDR benchmark exercise design data," CEA draft technical appendix, rev. 7, Novembre 2005, http://www.gcfr.org/. 

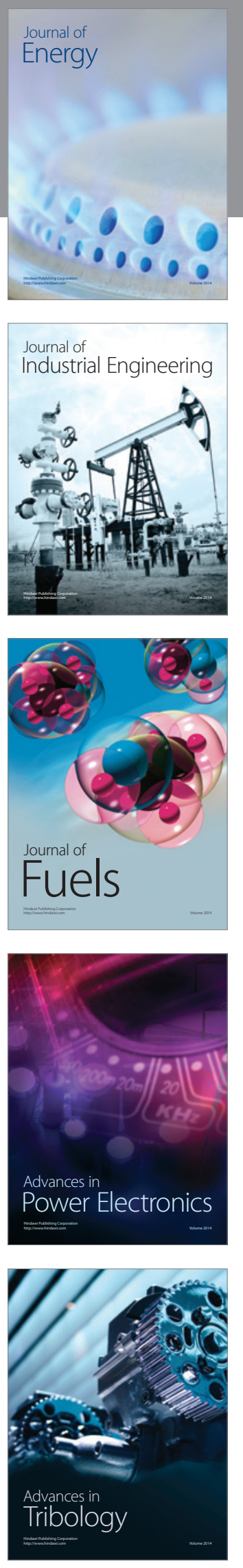
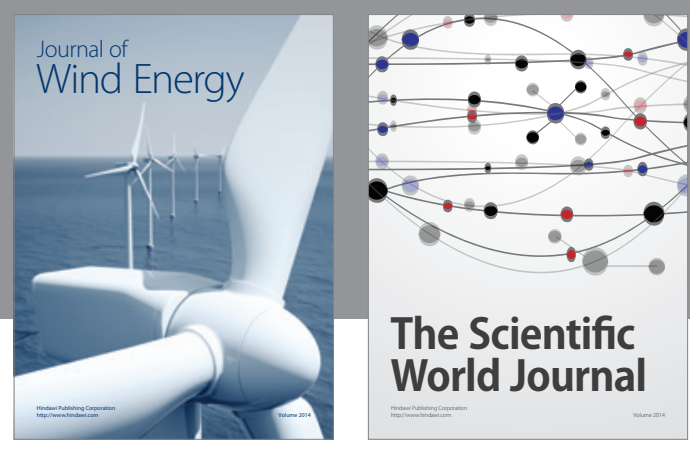

The Scientific World Journal

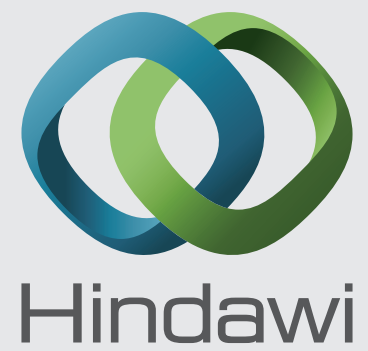

Submit your manuscripts at http://www.hindawi.com
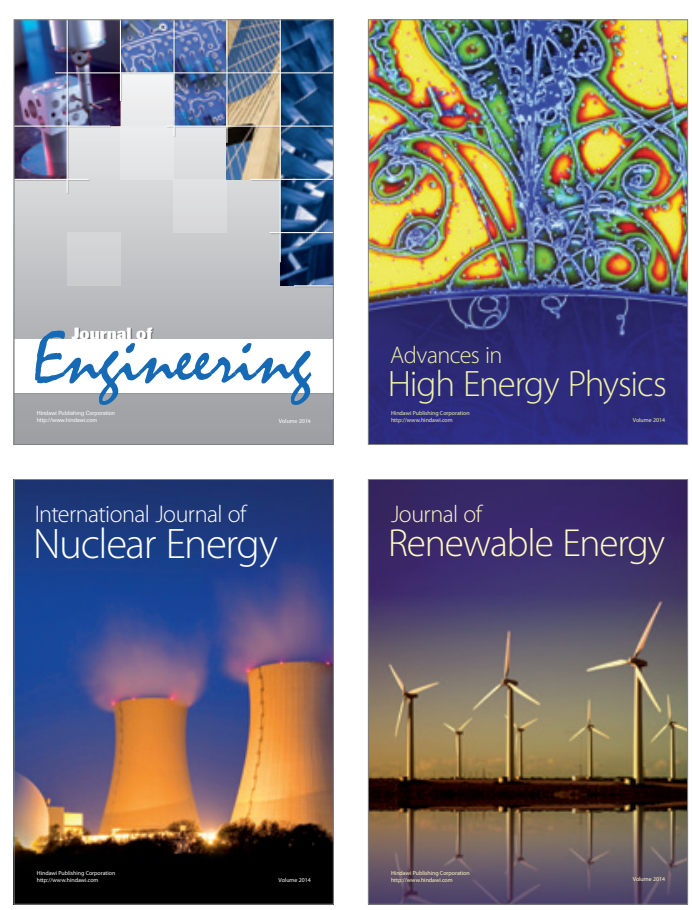

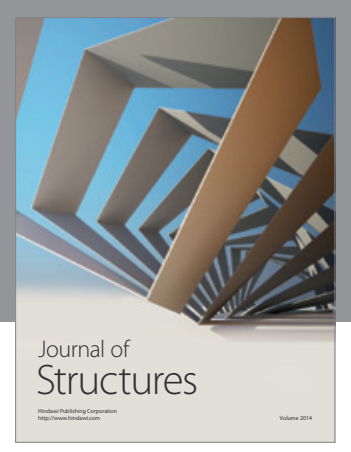

Rotating
Mechinery
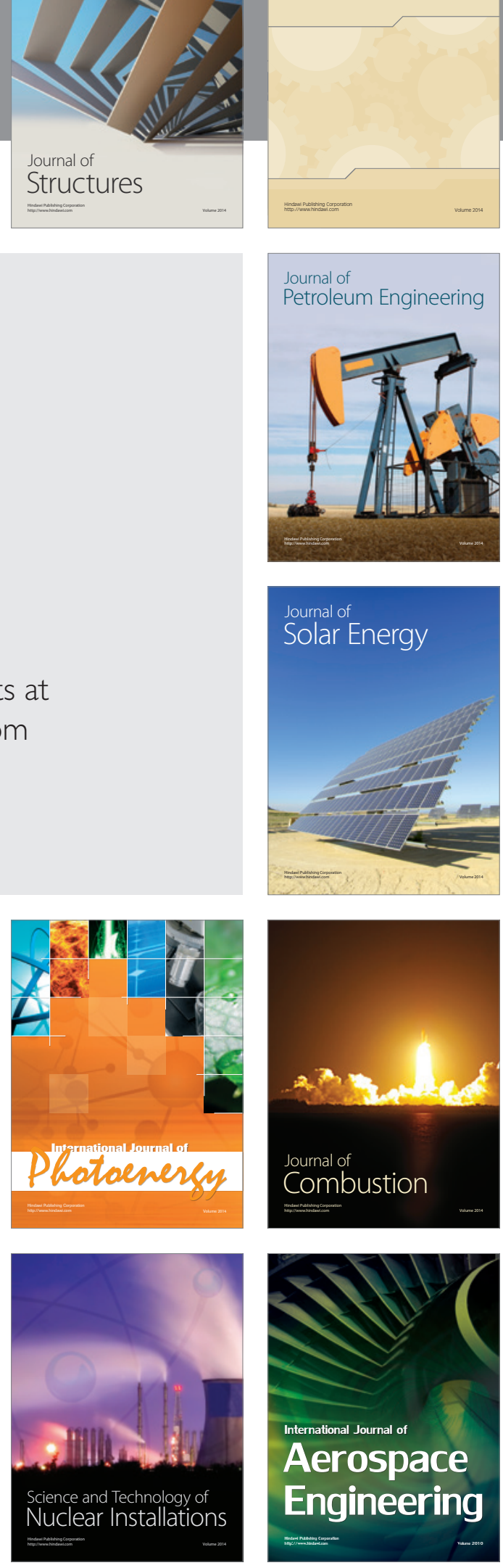